\title{
O ambiente, o virtual e a aprendizagem no núcleo de percepção visual do AVA-AD
}

\author{
Ana Zeferina Ferreira Maio* \\ Alice Cybis Pereira**
}

\begin{abstract}
Resumo Este artigo descreve a criação do núcleo de percepção visual no Ambiente Virtual de Aprendizagem em Arquitetura e Design (AVA-AD) da UFSC. Para tanto, apresenta o referencial teórico e a estrutura tecnológica que apóiam o processo de aprendizagem colaborativa no ambiente. Fundamenta-se na aprendizagem baseada na resolução de problemas (ABP) e no potencial das tecnologias de informação e comunicação. Aborda a metodologia adotada no desenvolvimento do núcleo virtual e finaliza analisando os resultados do curso de "Percepção visual e linguagem de vídeo", no qual um grupo de estudantes solucionaram problemas de percepção visual na plataforma do AVA-AD.
\end{abstract}

Palavras-chave ambiente virtual de aprendizagem, percepção visual, linguagem de vídeo, aprendizagem colaborativa, tecnologias de informação e comunicação.

\begin{abstract}
This article describes the creation of a Center on visual perception in a Virtual Learning Environment on Architecture and Design of the Federal University of Santa Catarina. Thus, it presents the theoretical approach and the technological structure that supports the process of collaborative learning in such an environment. Problem Based Learning (PBL) approach provides theoretical referential to the study as well the potential of technologies of information and communication. Also, the article discusses the methodology used on the development of the virtual nucleus and the analysis of the course "Visual Perception and Language of Video", in which a group of undergraduate students in design at UFSC had solved problems of visual perception through Virtual Learning Environments.
\end{abstract}

Keywords virtual learning environment, visual perception, video language, collaborative learning, technologies of information and communication.

\section{A inovação tecnológica e a educação diante das novas mídias}

O avanço tecnológico, a convergência do computador para as telecomunicações, a integração de serviços como dados, vozes e imagens, a explosão da internet e a world wide web estão possibilitando uma maior democratização das informações. Potencialmente qualquer indivíduo

\footnotetext{
* Professora Adjunta do Departamento de Letras e Artes da FURG

** Professora Titular do Departamento de Expressão Gráfica/ UFSC
} 
"conectado" pode fazer parte da rede mundial de informações chamada ciberespaço. Nesse sentido, o ciberespaço é muito mais do que um meio de comunicação ou uma mídia, pois ele reúne, integra e redimensiona uma infinidade de mídias e uma pluralidade de interfaces, permitindo que as informações - orientadas sob o signo da velocidade - atravessem oceanos, continentes e hemisférios, conectando os indivíduos numa infinita rede de acesso a saberes e transmissão dos mesmos.

Nas últimas décadas há uma espécie de discurso consensual sobre o caráter revolucionário e sem precedentes das transformações tecnológicas do período digital para a sociedade atual. Dentro desse cenário, as informações renovam-se com uma velocidade espantosa e a demanda por formação e qualificação profissional assume um lugar de destaque no redimensionamento da relação indivíduo-trabalho, pois estar em constante processo de atualização tornou-se condição obrigatória, tanto para o indivíduo se inserir no mercado de trabalho, quanto para nele permanecer. Com efeito, cresce mundialmente o reconhecimento das potencialidades que a educação a distância oferece como alternativa e complemento à educação presencial. ${ }^{1}$

Nesse processo, as tecnologias de informação e comunicação, particularmente a integração das redes informatizadas, buscam responder, mesmo que em parte, às atuais exigências de mercado e os ambientes virtuais de aprendizagem (AVAs) são um exemplo disso. Os AVAs, sintonizados com os novos paradigmas epistemológicos da educação, privilegiam a aprendizagem colaborativa, a construção compartilhada do conhecimento, a interatividade, a subjetividade, a autonomia e o desenvolvimento de uma consciência crítica nos estudantes. Atraídos pelo potencial sócio-técnico dos ambientes de aprendizagem, que fazem do digital seu suporte e pela possibilidade de constante atualização, muitos educadores têm se utilizado do ciberespaço como um meio para a renovação de suas práticas pedagógicas.

Por conseqüência, os ambientes virtuais de aprendizagem representam uma importante contribuição do sistema educativo ao contexto de inovação das tecnologias de informação e comunicação, através da invenção de novos usos desses artefatos. Paralelamente, os novos dispositivos tecnológicos ampliaram e transformaram as práticas pedagógicas, favorecendo o atendimento às demandas das sociedades contemporâneas, principalmente em sua tendência à individualização.

Assim o campo de motivação deste estudo está relacionado às transformações da aprendizagem na atual sociedade da informação, ao desenvolvimento das tecnologias de informática a serviço da inteligência coletiva; ao aumento do número de indivíduos que dependem da informação para sobreviver nas sociedades complexas com novos formatos de trabalho e profissões; com a nova ordem econômica, social e cultural, instaurada mundialmente pela era digital, e com a própria economia, sustentada pela informação, circulando como uma moeda corrente.

\section{O projeto AVA-AD e a criação do núcleo de percepção visual}

Este trabalho originou-se do projeto "Ambiente Virtual de Aprendizagem em Arquitetura e Design (AVA-AD)", desenvolvido no Laboratório de Hipermídia (Hiperlab), do Departamento

\footnotetext{
${ }^{1}$ O Artigo 80 da LDB (Lei 9.394/96) - primeira referência da EAD na legislação brasileira - e a criação da Secretaria de Educação a Distância (SEED) pelo MEC são indicadores deste reconhecimento (ver: www.mec.gov.br).
} 
de Expressão Gráfica, da Universidade Federal de Santa Catarina. ${ }^{2}$ O AVA-AD tem como objetivo estruturar, em termos pedagógicos e tecnológicos, ambientes de aprendizagem específicos para áreas que utilizam linguagem gráfico-visual. Destina-se a atender um público graduado em Arquitetura, Design e áreas relacionadas, que buscam atualização de conhecimento, assim como estudantes em processos de conclusão de curso e profissionais que procuram material de apoio para pesquisas nas especificidades anteriormente citadas.

Os núcleos de aprendizagem do AVA-AD estão centrados em três áreas, a saber: fundamentação, projeto e educação. A primeira reúne os núcleos de forma, luz, cor e textura. A área de projetos é constituída de metodologia, tecnologia e sustentabilidade. E por fim, a área de educação visa à formação profissional e à educação de nível fundamental e médio, através do Design.

Com base nessa estrutura - e particularmente em função da existência dos núcleos de forma, luz, cor e textura - identificou-se a necessidade de desenvolver um núcleo de aprendizagem da percepção visual, complementando e interligando, assim, as pesquisas já existentes.

Diante das atuais transformações operadas no sistema educacional e diante do desenvolvimento nos campos da informática e das telecomunicações, nosso problema constitui-se em estruturar, em termos pedagógicos e tecnológicos, o núcleo de percepção visual, visando contribuir para a aprendizagem no AVA-AD, assim como reforçar a necessidade de pesquisas, as contribuições dos fenômenos que envolvem aspectos técnicos e sociais nas novas maneiras de constituição e transmissão do conhecimento.

Por conseqüência, o núcleo de percepção visual do AVA-AD abordou de modo interdisciplinar os temas a que se refere e buscou interferir nas ações tradicionais de ensino cujo foco é a percepção visual, distanciando-se de teorias e modelos de aprendizagem nos quais os processos de ver e criar são entendidos como a-históricos, e aspectos referentes ao contexto cultural, político e social da percepção dos indivíduos são desconsiderados.

No caso citado, o estudo da percepção foi associado à linguagem visual do vídeo, que desempenhou a função de elo entre as visões práticas e empíricas do fenômeno perceptivo, pois os signos são as únicas formas de síntese de que dispomos para a ligação entre os mundos exterior e interior.

Se inovar significa transformar algo através da introdução do novo, a inovação que aqui defendemos deve se dar no campo social, associada simultaneamente à utilização de novas tecnologias, que permitam outras formas de contato e interação, e novas posturas pedagógicas que estimulem novas maneiras de perceber e interpretar a realidade diante de práticas que se mostram inadequadas. Por isso mesmo, este estudo não sustenta seu diferencial apenas por se dar em um ambiente virtual, mas busca destacar-se pela profundidade e abordagem integrada dos conteúdos e, sobretudo, pela ênfase na especificidade das linguagens visuais.

Desse modo, o presente trabalho pode ser aproximado daquilo que Belloni denomina de "mediatização pedagógica", ao referir-se à noção de "educação para as mídias", propondo a formação de um usuário ativo, crítico e criativo em relação às tecnologias de informação e comunicação. A autora afirma que a possibilidade de abarcar a complexidade deste debate seria estimular uma apropriação ativa e criativa das mídias por parte dos professores e dos alunos. Para tanto, as mídias precisariam ser integradas em sua dupla dimensão: como ferramenta

\footnotetext{
${ }^{2}$ Este projeto é financiado pelo CNPq desde 2001, através da concessão de bolsas, e é coordenado pela Prof ${ }^{\mathrm{a}}$. Alice Cybis Pereira, PhD.
} 
pedagógica (em termos instrumentais e conceituais) e como objeto de estudo (em termos estéticos e éticos).

Suas características essenciais - simulação, virtualidade, acessibilidade, a superabundância e extrema diversidade de informações - são totalmente novas e demandam concepções metodológicas muito diferentes daquelas metodologias tradicionais de ensino baseadas num discurso científico linear, cartesiano e positivista. Sua utilização com fins educativos exige mudanças radicais no modo de compreender o ensino da didática (BELLONI, 1999, p. 15).

Mediatizar, neste estudo, significa escolher para um determinado contexto e situação de comunicação, o modo mais eficaz de assegurá-la, e selecionar o meio mais adequado a tal fim. Sendo assim, o ambiente virtual de aprendizagem colaborativa - lugar onde as informações visuais dos projetos são acessadas, anexadas e alteradas, individualmente ou em grupo, de forma síncrona ou assíncrona - deve suportar o uso de imagens fixas (fotografias) e em movimento (vídeo), com a finalidade de alcançar as seguintes funções:

a) objetos de estudo da aprendizagem baseada em problemas,

b) objetos de estímulo à criação e análise de imagens.

Tal estratégia, do núcleo de percepção visual, visa assegurar a integração entre teoria e prática dos conteúdos abordados, bem como enfatizar a linguagem visual, através do uso de sistemas de signos não-verbais nos enunciados dos problemas, diferenciando-se dos ambientes virtuais de aprendizagem, centrados basicamente no uso da linguagem verbal. O núcleo de percepção visual do AVA-AD busca afastar-se da mera reprodução das práticas do ensino presencial, fato que confirmaria, entre outros aspectos, uma subutilização dos dispositivos tecnológicos.

\section{AVA-AD: referencial teórico e estrutura tecnológica}

O processo de aprendizagem da percepção visual no AVA-AD apóia-se nos pressupostos da aprendizagem baseada em problemas (ABP), no potencial das tecnologias da informação e comunicação (TIC), que buscam facilitar a gestão do conhecimento na comunidade virtual através da aprendizagem colaborativa à distância e na teoria dos conteúdos específicos de cada núcleo de aprendizagem (TC).

As atividades pedagógicas do AVA-AD ressaltam o aprendizado colaborativo, com base em processos cooperativos, visando diminuir as incertezas do aprendiz, mediante a resolução de problemas. Nesse caso, a ABP foi definida como a principal estratégia pedagógica do ambiente devido às suas características, tais como buscar desenvolver no estudante habilidades para lidar com situações-problema, ajudando-o a adquirir competência e autonomia para gerir o seu próprio processo de aprendizagem. Por efeito, postulamos que a ABP é adequada para atender a atual demanda por qualificação profissional de alunos adultos, a necessidade de metodologias 
aplicáveis à EAD, a expectativa das sociedades modernas no que se refere à valorização de mudanças, e principalmente a tendência social à prática de individualização.

Um dos maiores desafios da mediação pedagógica em um AVA é a complexidade organizacional do ambiente, ou seja, sua logística. A questão diz respeito, entre outros fatores, à comunicação e à interação da comunidade virtual, para alcançar o objetivo de uma aprendizagem colaborativa. No presente caso, inicialmente foram definidos o design, as interfaces e os canais de comunicação que seriam disponibilizados aos aprendizes. Tais aspectos do ambiente são fundamentais, pois afetam a qualidade, a natureza e o volume de interação; portanto, interferem diretamente nos benefícios cognitivos e motivacionais da aprendizagem.

No que concerne às estratégias de aprendizagem, aos recursos e ferramentas tecnológicas e às possibilidades de interação e comunicação, o AVA-AD está estruturado a partir de quatro eixos, a saber: documentação, produção, informação e comunicação (Figura 1).

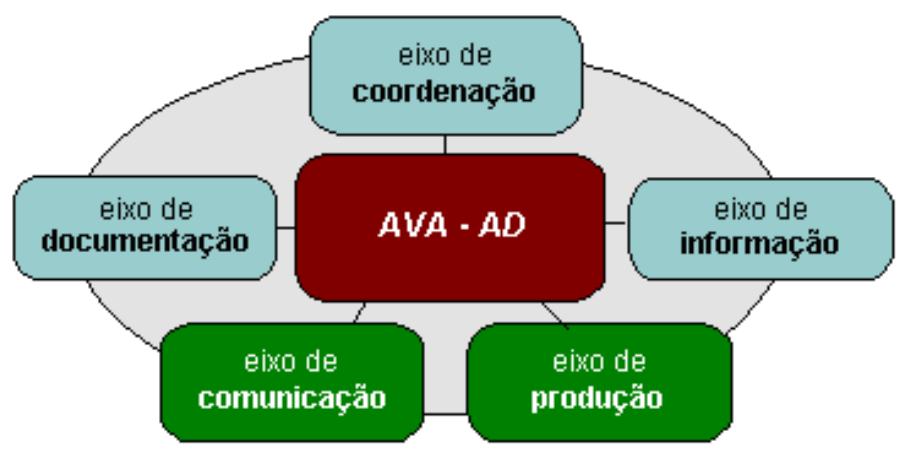

Fonte: Adaptação de Gonçalves, 2004.

Figura 1: Eixos que organizam as ferramentas disponíveis no AVA AD

Cumpre ressaltar que os quatro eixos referidos, no contexto do ambiente AVA-AD, não estão isolados, pois foram organizados a partir da natureza de suas atividades e podem ser acessados por diferentes caminhos, porque apresentam uma estrutura não-linear.

O eixo de documentação é composto por banco de imagens, banco de textos, material didático, vídeos, animações e galeria de trabalhos desenvolvidos pelos alunos, permitindo aos usuários que o ambiente seja consultado em qualquer lugar e a qualquer momento. $\mathrm{O}$ aprendiz é orientado a ter uma pasta, na qual ele reunirá e organizará um arquivo com dados de consulta.

No eixo de informação, estão disponíveis as informações de apoio à resolução dos problemas e das atividades colaborativas. Nesse caso, há um glossário específico elencando os conteúdos, as teorias relacionadas, bem como sugestões de estudos adicionais, dicas, bibliografias complementares, artigos e sites relacionados aos temas abordados. O conjunto de conteúdos é estruturado de forma hipertextual, podendo ser acessado de acordo com o interesse individual do aluno.

O eixo de produção do AVA-AD apresenta uma seqüência de problemas, no qual o aprendiz busca articular a teoria dos conteúdos à prática da resolução dos mesmos. O eixo de comunicação conta com diversas ferramentas, que visam dar suporte às atividades pedagógicas 
desenvolvidas no AVA-AD. Desse modo, as ferramentas de $e$-mail, chat e fórum de discussão apóiam e facilitam a interação entre aprendizes/aprendizes, aprendizes/tutores, aprendizes/professores. $\mathrm{O}$ ambiente colaborativo 2D e 3D inclui a área de chat e a área gráfica, onde as informações visuais dos projetos podem ser acessadas e analisadas em grupo, de forma síncrona ou assíncrona, em modalidades interativas um-um, um-todos e todos-todos.

\section{Concepção do núcleo de percepção visual do AVA-AD}

Os objetivos do núcleo de percepção visual foram assim definidos:

a. favorecer o desenvolvimento da percepção visual e potencializar a capacidade crítica e criativa para análise e criação de imagens;

b. promover experiências de aprendizagem a respeito da percepção visual, através da resolução de problemas, com o recurso de linguagens visuais;

c. proporcionar aprendizagem colaborativa em um ambiente mediado pelo uso de mídias digitais integradas, sensibilizando os usuários no potencial das tecnologias de informação e comunicação, através de processos vinculados ao saber, saber fazer, saber ser e saber conviver;

d. investigar formas visuais de representação artística e estética;

e. instrumentalizar os alunos na logística pedagógica do ambiente do AVA-AD e no uso de novas tecnologias.

As estratégias educacionais para atingir os objetivos do núcleo de percepção visual incluíram:

a. identificação das necessidades e interesses dos aprendizes,

b. criação de problemas para resolução colaborativa;

c. integração dos núcleos de cor, forma, luz e textura;

d. promoção da interação da comunidade virtual colaborativa;

e. seleção e sistematização dos conteúdos teóricos, identificando diferentes níveis de complexidade;

f. exploração dos recursos visuais;

g. organização do apoio técnico e pedagógico;

h. processos de avaliação, com base na participação on-line, envolvimento com as discussões propostas nos fóruns, etapas de desenvolvimento dos problemas, adequação e articulação entre teoria e prática, criação e análise do projeto, relação entre processo e produto.

O desenvolvimento do ambiente envolveu a definição de estratégias pedagógicas e tecnológicas para os eixos de documentação, informação, comunicação e produção, tais como: 
a. estruturação dos conteúdos (valorizando aspectos hipertextuais) sobre percepção visual de modo a integrá-los aos outros núcleos (cor, forma, textura e luz) de aprendizagem do AVA-AD;

b. definição de diferentes níveis de complexidade e sintetização dos conteúdos;

c. criação de recursos audiovisuais (fotografias e vídeos) utilizados na aprendizagem baseada em problemas;

d. definição e classificação hierárquica dos problemas, para investigação e resolução colaborativa, através de propostas de análise e criação de imagens videográficas;

e. elaboração de instrumentos para gestão interativa do conhecimento, apoio técnico (ferramentas de colaboração) e apoio pedagógico;

f. definição dos instrumentos de avaliação, considerando-se os aspectos tecnológico e pedagógico;

g. desenvolvimento de interfaces, considerando aspectos gráfico-visuais (imagens 2D ou 3D, estáticas ou em movimento, e portfólios dos alunos), e fatores ergonômicos (usabilidade, funcionalidade e estética).

\section{Implementação e validação do modelo}

Esta etapa compreendeu a implementação do modelo (itens anteriormente citados) de núcleo de percepção visual na plataforma do AVA-AD. Após a estruturação do núcleo e efetiva disponibilização no site, foi realizado um estudo piloto, no qual um grupo desenvolveu as atividades propostas, sendo avaliados os níveis de interação e a profundidade das contribuições dos estudantes, as soluções propostas aos problemas, a navegabilidade do ambiente, as dificuldades técnicas e a necessidade de apoio pedagógico e tecnológico, indicando os aspectos que podem ser aperfeiçoados.

\section{A definição da clientela}

O processo de validação do modelo do núcleo de aprendizagem sobre percepção visual do AVAAD ocorreu na forma de Projeto de Extensão, através do curso intitulado "Percepção Visual e Linguagem de Vídeo", realizado na Universidade Federal de Santa Catarina, durante o período de 10 de novembro a 15 de dezembro de 2004.

Os participantes foram estudantes da $6^{\circ}$ e $7^{\circ}$ fases da disciplina de Vinheta Eletrônica, do Curso de Comunicação e Expressão Visual, lotado no Departamento de Expressão Gráfica da UFSC. A definição da clientela se deu a partir de negociações com o Prof. Augusto Fornari, responsável pela referida disciplina, durante as quais lhe foi apresentado o conteúdo programático, objetivos, procedimentos metodológicos e bibliografia do curso. 
Por ser a clientela a essência do processo do planejamento, procedeu-se a uma espécie de diagnóstico para determinar interesses, necessidades, contexto cultural, características gerais, motivações e domínio tecnológico, com o objetivo de auxiliar as características da modelagem do sistema. Um dos critérios norteadores da escolha deste grupo foi tratar-se de uma turma de aprendizes com conhecimento básico em software de criação e edição de vídeo como Adobe Premiere, After Effects e Animatic. Além disso, são desenvolvidas na disciplina de Vinheta Eletrônica experiências práticas em vídeo, tais como: sincronização de áudio e imagem, edição não-linear e teoria de animação.

No entanto, embora os estudantes recebessem variados conhecimentos técnicos em vídeo para serem aplicados ao Design, o próprio professor reconhecia uma lacuna relacionada ao estudo da linguagem videográfica e da percepção visual. Nesse caso, o curso em questão buscou atender uma demanda intelectual através de um processo de complementação pedagógica.

O próximo passo foi um encontro com a turma de "Vinheta Eletrônica", no qual foi apresentada a proposta do projeto de extensão, exigências do curso e esclarecimentos do funcionamento do AVA-AD. Foi estabelecido como pré-requisito disponibilizar uma carga horária de 4 horas semanais, durante cinco semanas, totalizando uma participação de 20 horas. A definição do período deveu-se, entre outros aspectos, ao fato de que haveria tempo suficiente para a realização das atividades previstas, navegar e se adaptar ao ambiente, acessar os conteúdos disponibilizados e aplicá-los na resolução de dois problemas.

Ficou acertado que os estudantes interessados se cadastrariam junto ao site do AVA-AD e, para nossa surpresa, os vinte aprendizes da turma realizaram seus cadastros. Conforme previsto, no dia 10 de novembro de 2004, o curso iniciou com a exibição de uma série de vídeos seguida de um debate cuja tônica foi a percepção e a linguagem visuais. O conceito de diversidade cultural norteou a mostra, portanto, buscou-se exibir produções videográficas de diversos artistas, localidades, épocas, com diferentes resultados poéticos.

Ao término da sessão, os estudantes se organizaram em quatro grupos de cinco participantes, e cada grupo escolheu um vídeo para proceder à análise das imagens. Ficou estabelecido que a configuração dos grupos seria a mesma durante todo curso. A partir deste encontro o acompanhamento dos trabalhos se deu somente através do ambiente virtual, com exceção do encontro de fechamento, que também foi presencial.

Após a aula inaugural do curso, foi realizado o cadastramento dos estudantes no site do AVA$\mathrm{AD}$, que implica a aprovação de um login e uma senha pela coordenadora geral do projeto. Esse processo é feito na página inicial do ambiente, onde constam quatro tópicos: conheça o AVA-AD, cursos oferecidos, curso demo e cadastre-se. No período referido havia ainda uma divulgação do Curso de Percepção Visual e Linguagem de Vídeo, conforme ilustra a figura 2. 


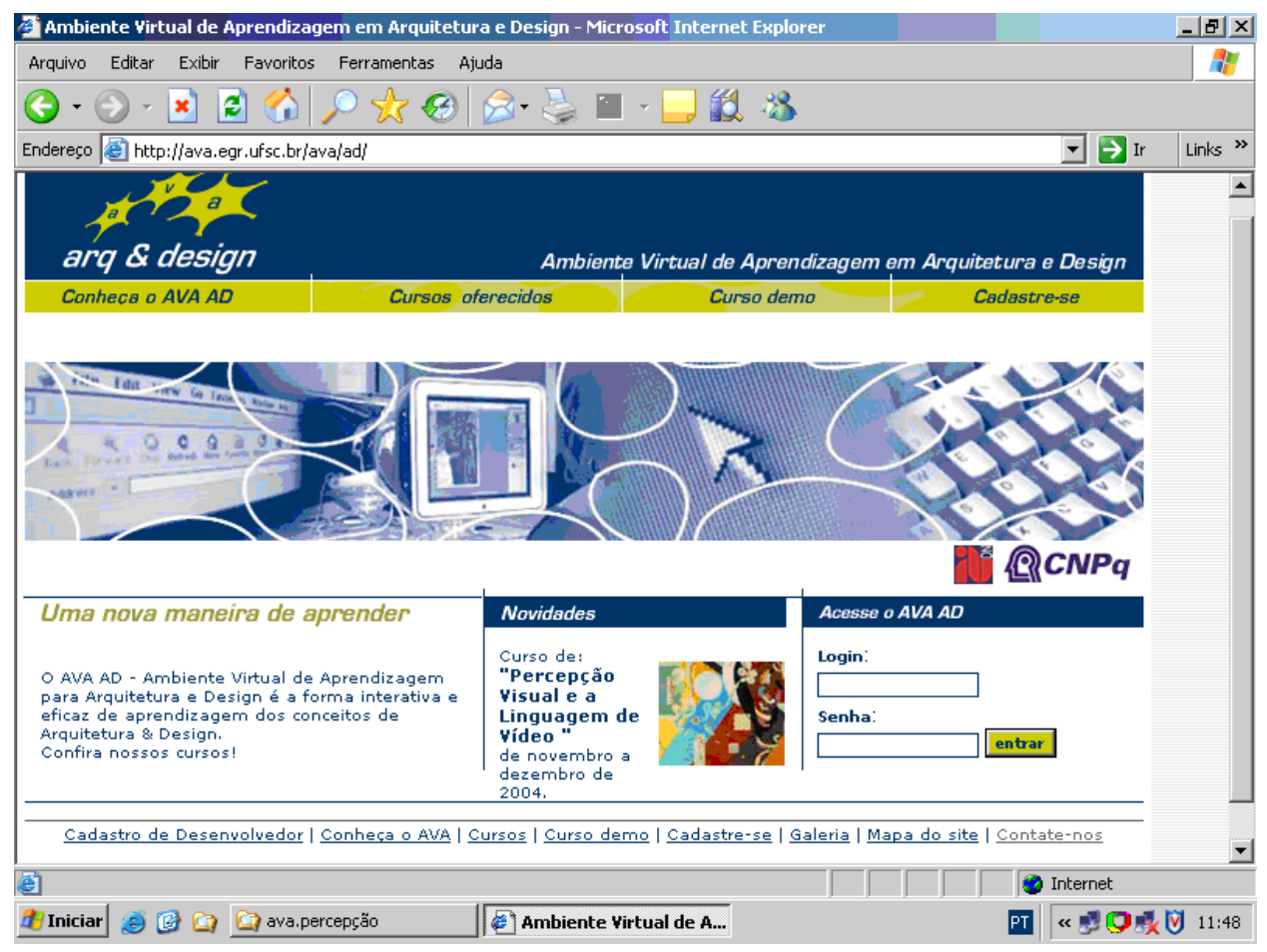

Figura 2: Imagem da interface inicial do AVA-AD com anúncio do curso "Percepção Visual e Linguagem de Vídeo". Fonte: AVA-AD (2005).

Uma vez realizado o cadastro, os aprendizes já podiam acessar o AVA-AD. No período inicial, o curso já estava estruturado, havia mensagem de boas vindas, encaminhamentos de tarefas, e os conteúdos e os problemas estavam implementados. Nessa fase do trabalho, foram destinados aos estudantes três dias para adaptação, reconhecimento da logística do ambiente e leitura dos conteúdos.

\section{Meu espaço virtualizado e a apresentação do ambiente de aprendizagem}

Na tela "Meu Espaço" foram disponibilizados todos os avisos do curso. A participação dos estudantes nas diferentes tarefas, bem como a pontualidade na entrega dos trabalhos demonstrou a eficiência desse espaço de comunicação. Na parte superior da interface da plataforma AVA$\mathrm{AD}$ constam cinco tópicos: ambiente de aprendizagem, que remete à tela de apresentação geral do curso; meu espaço; comunicações, que dá acesso a mensagens; fórum; ambiente colaborativo 2D e ambiente colaborativo 3D; biblioteca e por fim o tópico de ajuda, no qual o participante pode falar com o professor, com o monitor, com o apoio técnico, com o webdesigner, formular perguntas e visualizar o fluxograma, conforme exibe a figura 3. 


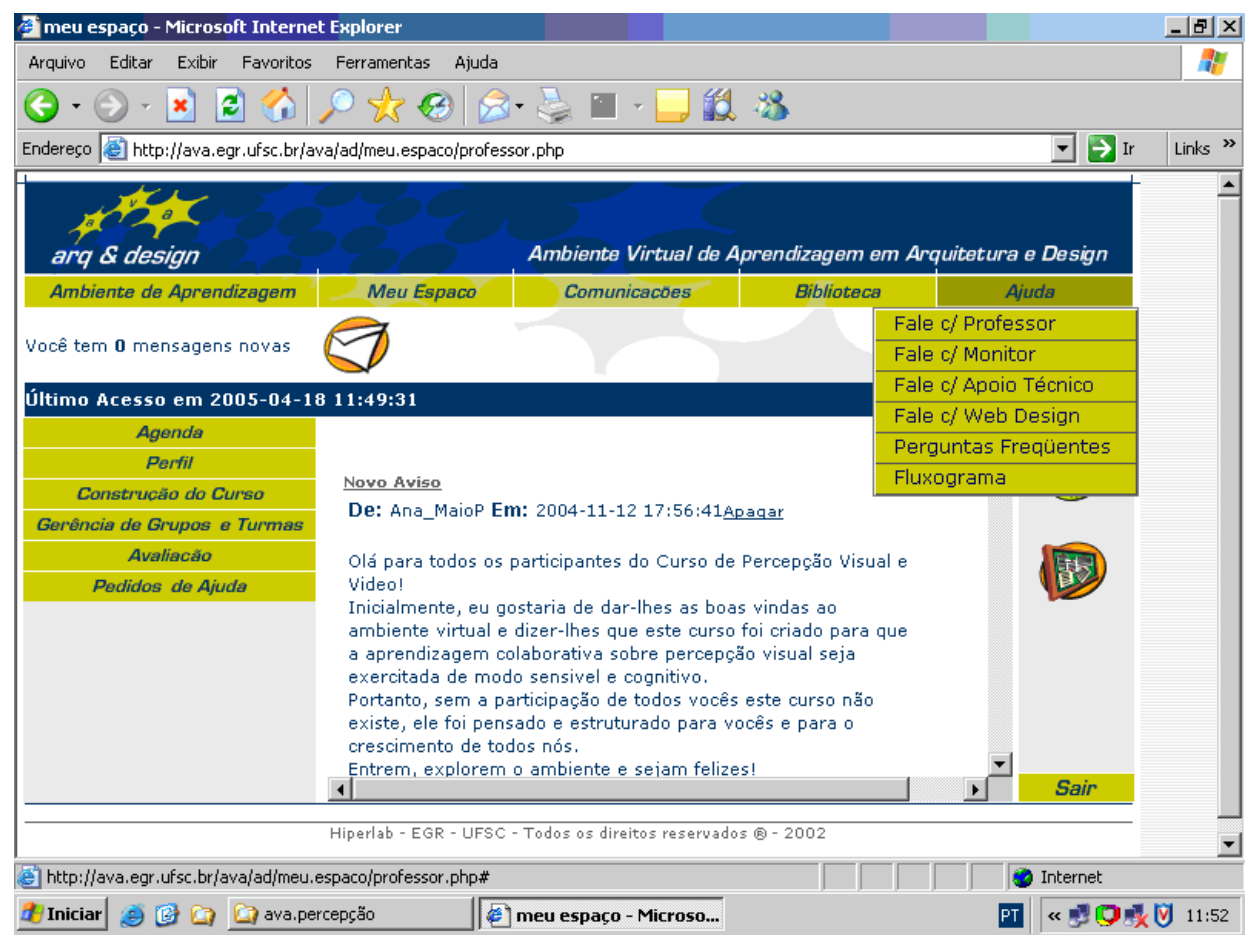

Fonte: AVA-AD (2005).

Figura 3: Interface da tela "Meu Espaço".

Na tela "Ambiente de Aprendizagem" há links para apresentação, conteúdos e problemas. Para esta tela foi realizada uma animação utilizando imagens do conjunto de obras do videoartista Nan June Paik; vídeos e fotografias realizados pela pesquisadora e uma série de mensagens que discorrem sobre os fenômenos perceptivos. No "Ambiente de Aprendizagem" a apresentação se desdobra em: texto de apresentação, plano de ensino e equipe, conforme mostra a figura 4. 


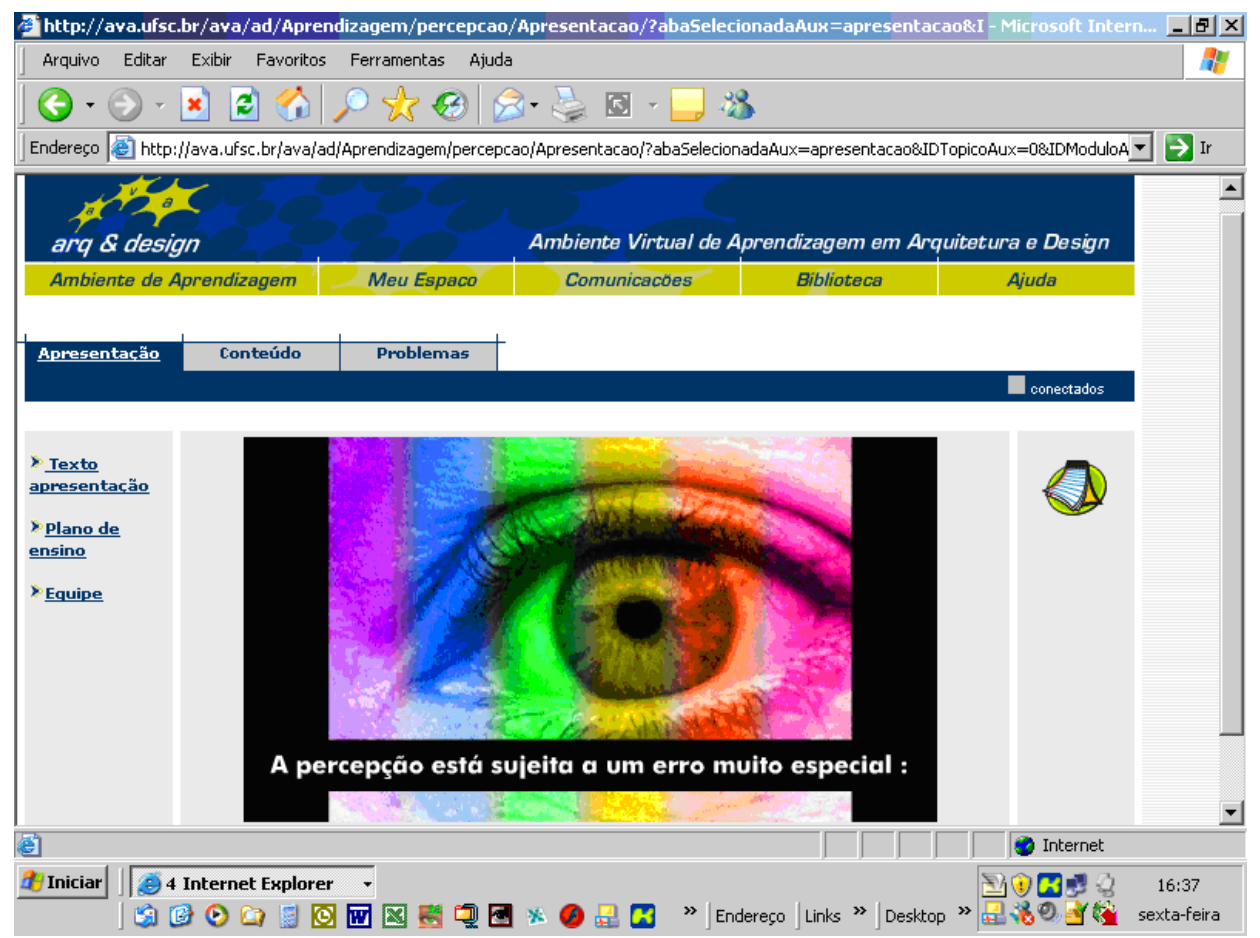

Fonte: AVA-AD (2005).

Figura 4: Interface da tela "Ambiente de Aprendizagem” com o vídeo de apresentação.

O texto de apresentação do núcleo de percepção visual informava aos aprendizes a preocupação do curso em oferecer atividades que ampliem a reflexão em torno da percepção visual, sobretudo a partir do senso estético, artístico e cultural. Para tanto, fundamentava-se em processos complementares de sensibilização, apreciação, fruição, análise e criação de imagens de vídeo, fomentando assim o pensamento poético.

As pesquisas em linguagem videográfica buscaram firmar um compromisso com a inovação tecnológica e a inventividade de imagens audiovisuais, priorizando novas formas de perceber e de produzir cultura. Sendo assim, o núcleo de percepção visual associou o conceito de educação visual ao compromisso contínuo com a inovação e a pesquisa, seja no âmbito das linguagens, do suporte, do material ou da temática.

No plano de ensino foi informado que o curso tinha como principal objetivo abordar a percepção visual numa articulação teórica e prática, através da aprendizagem colaborativa baseada na resolução de problemas. Portanto, buscou-se desenvolver a percepção visual através da experiência estética com vias a potencializar a capacidade crítica e criativa dos aprendizes para análise e criação de imagens videográficas. Como objetivos específicos foram estabelecidos:

a) sensibilizar os aprendizes para imagens artísticas e estéticas através de uma mostra de vídeo de diferentes gêneros;

b) integrar os conteúdos disponibilizados no ambiente virtual de aprendizagem na resolução colaborativa dos problemas; 
c) aprofundar o estudo da percepção visual e aplicá-lo na análise dos elementos constitutivos do código videográfico;

d) compreender a importância da percepção visual e aplicá-la na criação de projetos em vídeo;

e) desenvolver diferentes soluções para os projetos videográficos com ênfase na percepção do espaço e do tempo;

f) relacionar projeto, percepção visual e criação de imagens estéticas em vídeo.

O processo de aprendizagem baseou-se na resolução de dois problemas, o primeiro de análise e o segundo de criação de imagens videográficas, portanto ambos estimularam o estudo da percepção visual e foram resolvidos de modo colaborativo mediante a consulta e a integração dos conteúdos disponibilizados no AVA-AD. No que se refere ao sistema de avaliação, todas as etapas de desenvolvimento do curso foram avaliadas: participação na mostra de vídeos; participação e qualidade das intervenções nos fóruns de discussões; interação entre os membros dos grupos, e nas etapas de resolução dos problemas foram avaliadas a capacidade de adequação e articulação entre teoria e prática bem como a relação entre processo e produto. Os conteúdos foram apresentados no plano de ensino através do seguinte esquema:

\section{PERCEPÇÃO VISUAL}

1.1 Olho e processo visual

1.2 Elementos da percepção visual

1.3 Do visível ao visual

1.3.1 O espaço percebido

1.3.2 O movimento percebido

1.3.3 Movimento real e movimento aparente

1.4 Abordagens em percepção visual

\section{VIDEO}

\subsection{Conceito}

2.2 Etimologia do termo vídeo

2.3 O que é o vídeo?

\subsection{Histórico}

\subsubsection{Precursores da videoarte}

2.4.2 Nascimento da videoarte: Nam June Paik e a linguagem de vídeo 


\subsection{Classificação}

\subsubsection{Gêneros em vídeo}

2.5.2 Imagem videográfica e Design em movimento

\section{LINGUAGEM DO VIDEO}

\subsection{Percepção do espaço}

\subsubsection{Plano ou enquadramento}

\subsubsection{Angulação}

\subsubsection{Movimento de câmera}

\subsubsection{Cor naturalista e anti-naturalista}

\subsubsection{Textura e sobreposição}

3.1.6 Paisagem e cenário

\subsubsection{Imagem e palavra}

\subsubsection{Sistema sonoro}

\subsection{Percepção do tempo}

3.2.1 Corte, plano-sequiência e efeitos de transição

\subsubsection{Mudanças de velocidade}

\subsubsection{Montagem}

A primeira parte conceitua percepção visual, analisa as operações ópticas, químicas e nervosas que envolvem a visão e, portanto, a formação da imagem através do processo visual. Discorre acerca dos elementos da percepção visual: luz, cor e bordas; a passagem do visível ao visual, ou seja, a organização e interpretação do visível pelo sujeito que olha - a categoria da percepção visual; a percepção do espaço; e finaliza com uma análise em relação às principais abordagens da percepção visual. A segunda apresenta o vídeo em seus aspectos conceituais, históricos e classificatórios, e a terceira consiste em uma ampla análise das tendências da linguagem videográfica, articulando aspectos relativos à percepção do espaço e do tempo, ou seja, as duas principais dimensões da percepção visual. No processo de implementação dos conteúdos na plataforma do AVA-AD buscou-se valorizar os recursos da linguagem visual. As figuras 5, 6 e 7 exemplificam a questão. 


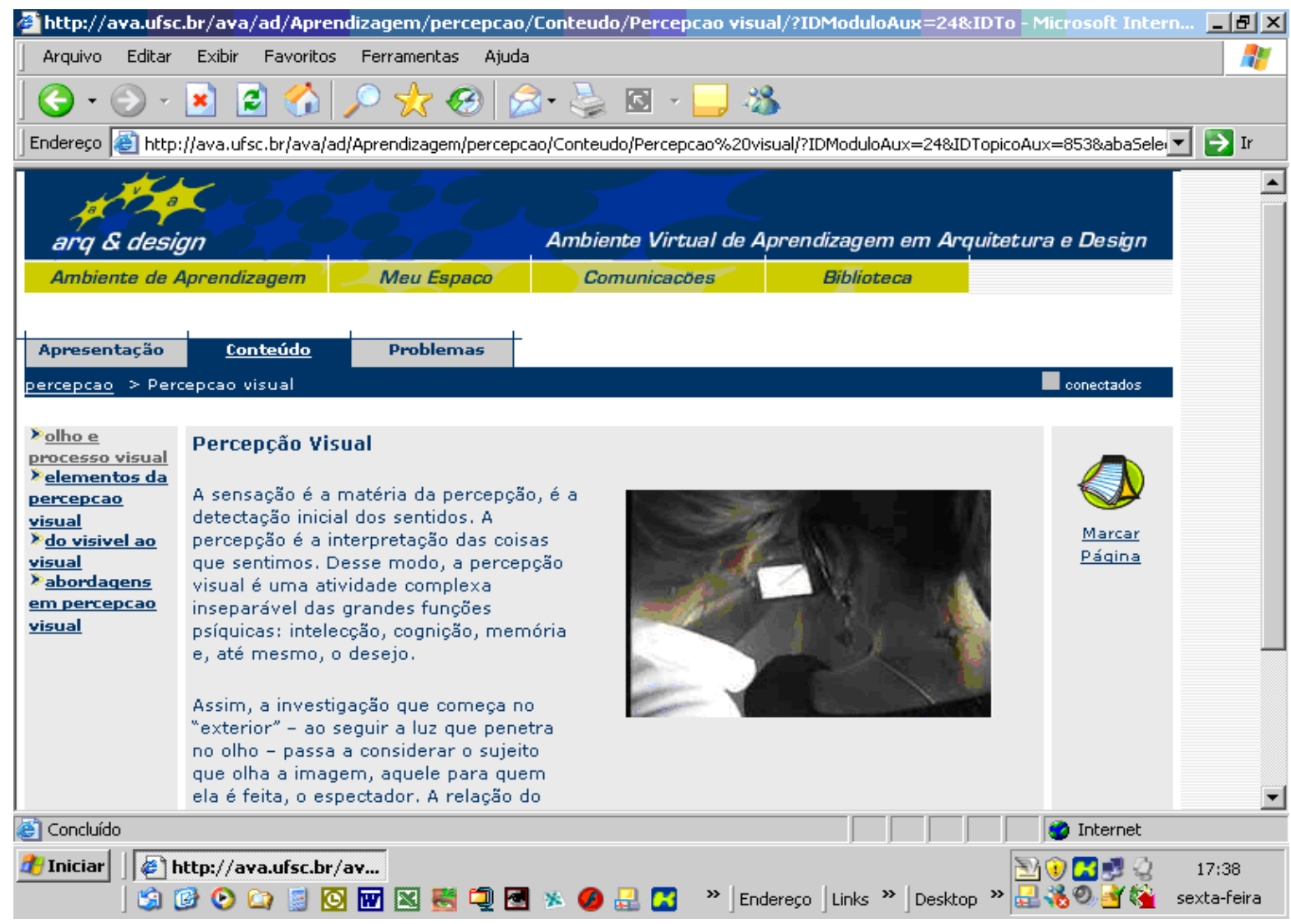

Fonte: AVA-AD (2005).

Figura 5: Interface do conteúdo "olho e processo visual", no site do AVA-AD. 


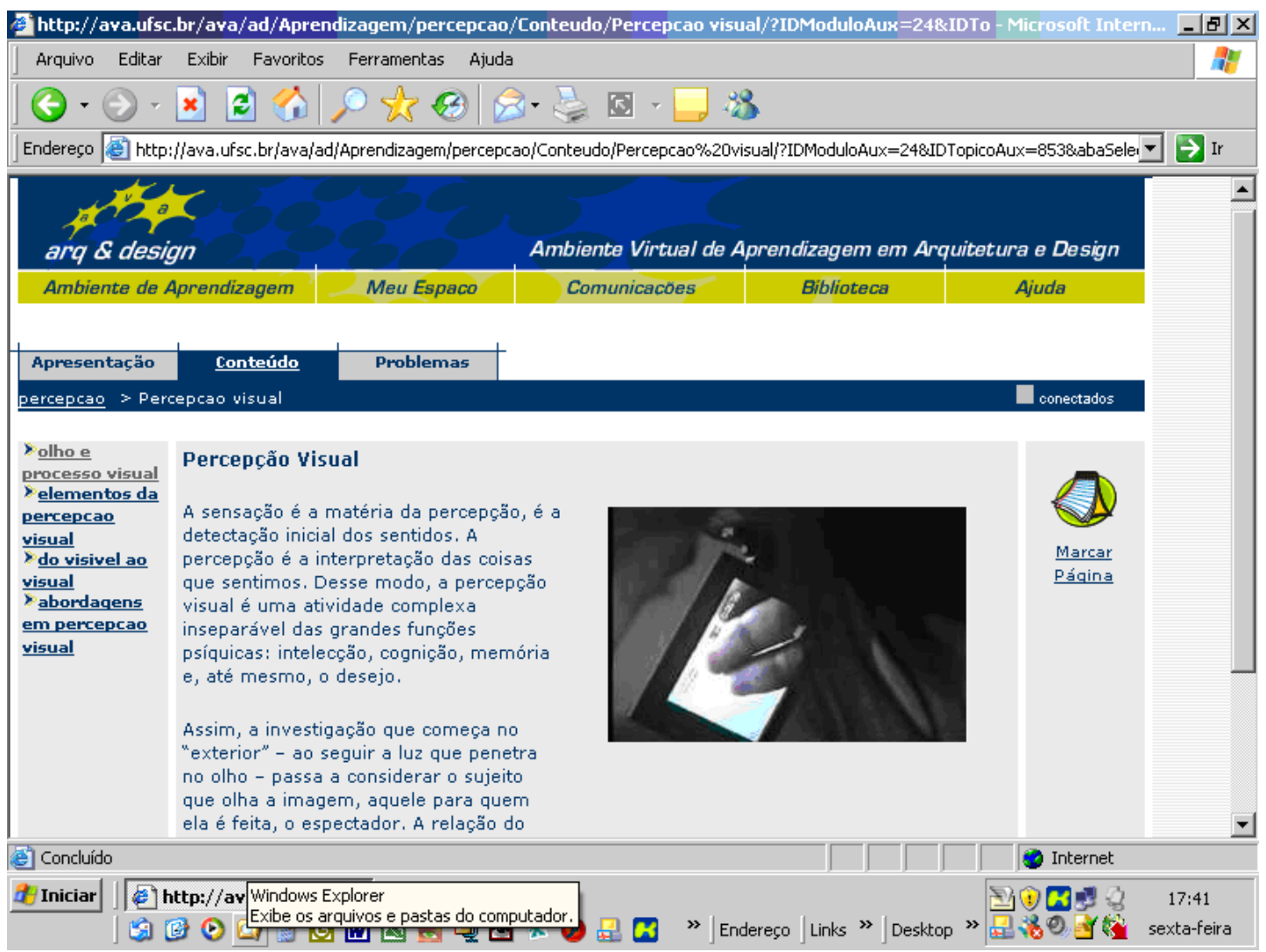

Fonte: AVA-AD (2005).

Figura 6: Interface do conteúdo "olho e processo visual", no site do AVA-AD. 


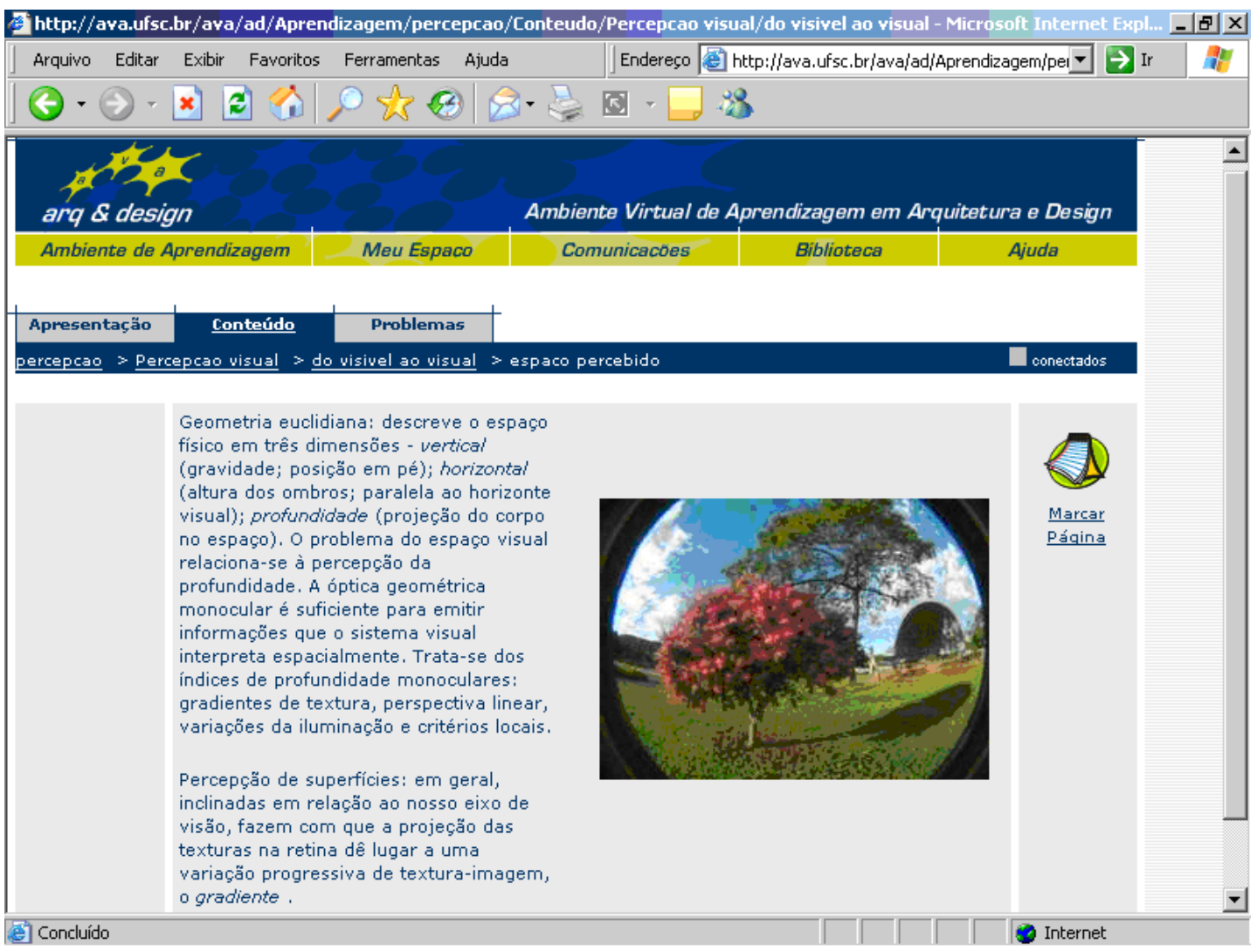

Figura 7 Interface do conteúdo "espaço percebido", no site do AVA-AD.

Fonte: AVA-AD (2005).

O terceiro tópico do "Ambiente de Aprendizagem" são os problemas, nos quais foi disponibilizado cenário, método, objetivos de aprendizagem, cronograma, material de apoio e critérios de avaliação, como mostra a figura 8. 


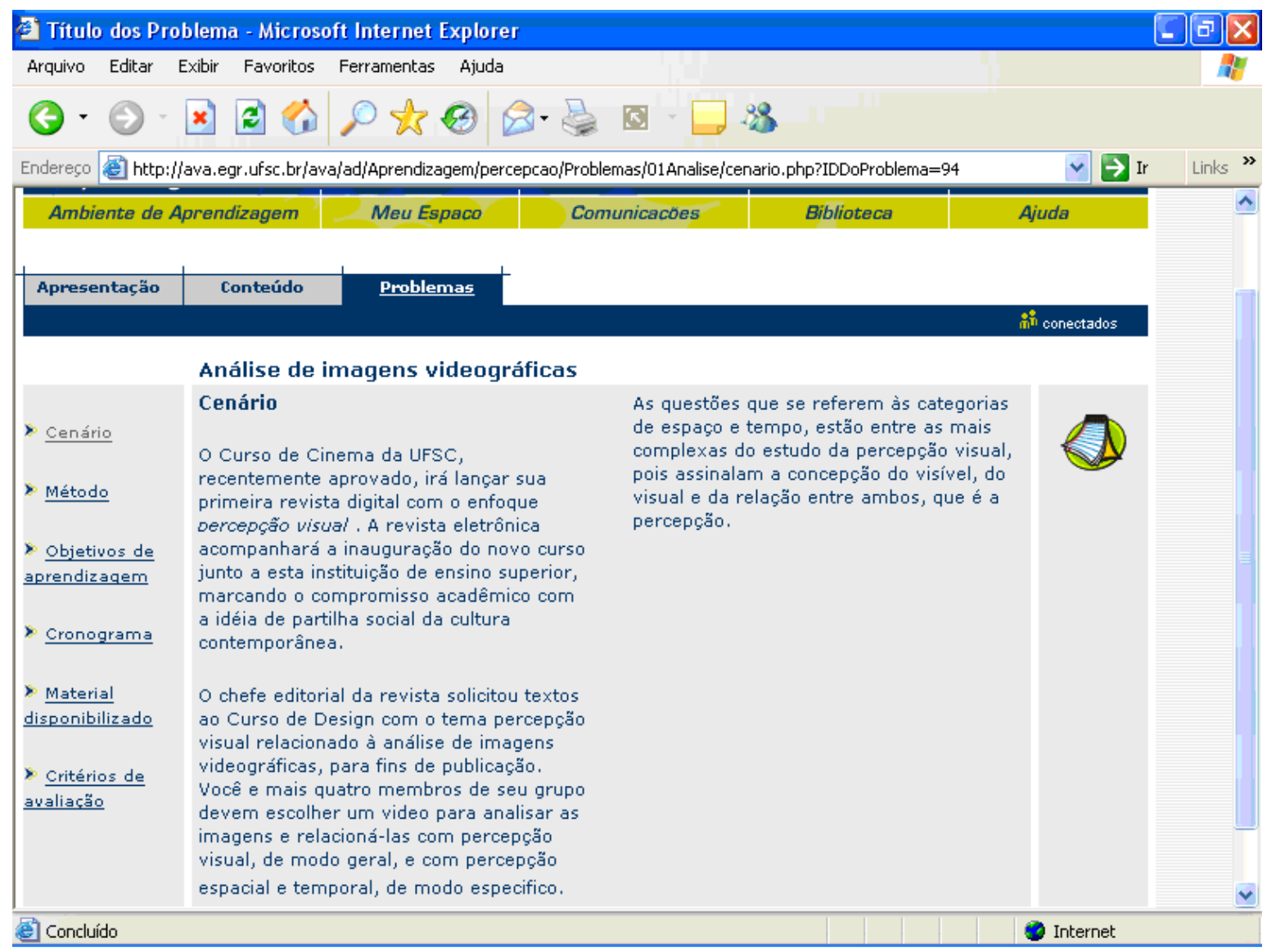

Fonte: AVA-AD (2005).

Figura 8: Interface do problema 1: “Análise de imagens videográficas”, no site do AVA-AD.

No dia 12 de novembro de 2004, teve início o fórum de resolução do primeiro problema, que consistiu em analisar as imagens dos vídeos exibidos na mostra. Nesse período, o acompanhamento das etapas de resolução dos problemas se deu sob a forma de discussões no fórum de turma que aborda temas comuns a todos os participantes e no fórum de grupo que trata das dificuldades específicas do grupo, como exibe a figura 9. 


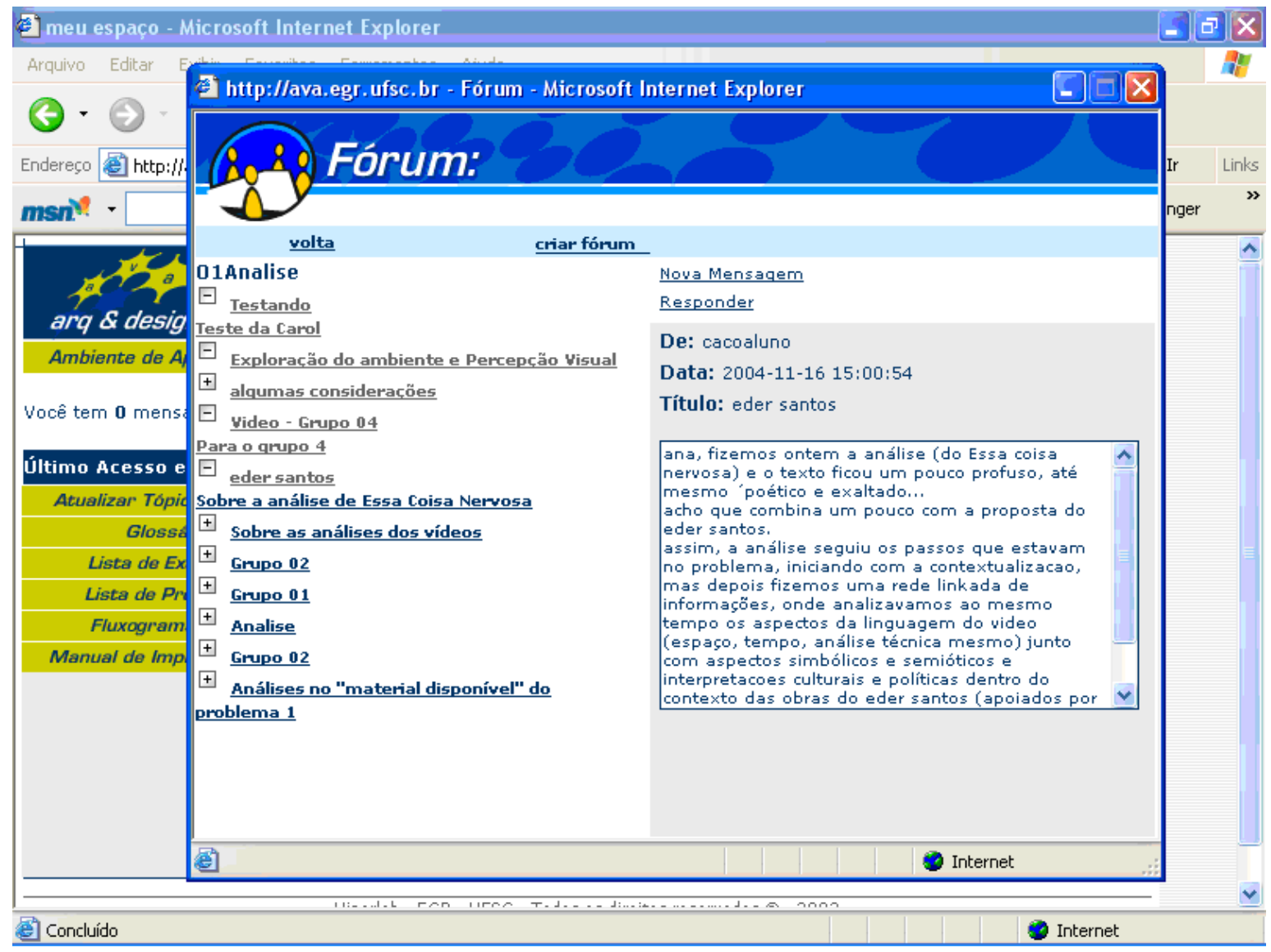

Figura 9: Interface do fórum de turma do problema 1: “Análise de imagens videográficas", no site do AVA-AD.

Fonte: AVA-AD (2005).

Os conteúdos de ambos os fóruns eram colocados em discussão pela professora numa espécie de provocação aos aprendizes, com o objetivo de gerar debate. Os resultados dos fóruns de discussões nos pareceram satisfatórios, pois os relatos e as trocas de informações entre os aprendizes e com a professora, durante as etapas de resolução dos dois problemas, nos permitiram avaliar que houve entendimento dos cenários, domínio dos conteúdos, qualidade na interpretação das leituras realizadas, bem como capacidade de articulação teórico-prática nas atividades de análise e criação dos vídeos. Por efeito, também demonstraram que a aprendizagem no ambiente deu-se de modo colaborativo, pois os estudantes participavam não somente dos fóruns de seus grupos, mas de outros de seus interesses, como mostra a transcrição abaixo.

De: hate_machine

Data: 17-11-2004

Título: Arnaldo Antunes

Não sou desse grupo, mas gostaria de comentar algo sobre aquele vídeo do Arnaldo Antunes que provavelmente deixou todo mundo confuso. Não lembro especificamente o nome do vídeo, mas era aquele que passava uma mensagem na tela com uma voz narrando outra coisa. 
Na hora fiquei realmente confuso, pois o texto estava muito legível e a narração também estava compreensível. No entanto, se me perguntarem qual era o assunto, confesso não saber responder.

Então fiquei pensando no motivo pelo qual fiquei assim, e a única explicação me veio através da semiótica. Parecia que eu tinha um estímulo visual e auditivo que afunilavam em um mesmo ponto na minha cabeça. Como se as letras e o som, apesar de serem captados por dois sensores distintos (visão e audição), tivessem que passar ao mesmo tempo pela mesma "caixa de tradução". Lembrei que na relação dos signos de Pierce, a linguagem escrita e verbal são categorizadas como símbolos, e a característica desses, é que são puramente convencionados. Talvez fosse esse o motivo do embaralhamento, e esse vídeo não tivesse nem a metade do efeito se fosse uma mistura de ícones com símbolos.

Só espero não ter viajado longe demais na maionese.

Abraços

No dia 19 de novembro de 2004, teve início o segundo problema com o objetivo de desenvolver a percepção visual através da criação de imagens videográficas. Os tópicos que constituíram a interface do problema foram: cenário, método, objetivos de aprendizagem, cronograma, material de apoio e critérios de avaliação. O mesmo apresentou três etapas de resolução: na primeira, foram solicitadas, aos aprendizes, leitura e interpretação do cenário, das dicas, dos conteúdos e dos textos disponibilizados (circuito de arte em deslocamento, cultura em deslocamento, linguagem da visão, tecnologias digitais). A segunda etapa envolveu a elaboração dos préprojetos de criação dos vídeos e a terceira implicou o processo de produção e edição destes.

A professora acompanhou todas as fases de desenvolvimento dos problemas, participando, instigando, esclarecendo, motivando e sistematizando os conteúdos. Nesse período, estabeleceuse como meta orientar os projetos, os conceitos e as linguagens dos vídeos. Assim, os debates envolveram questões técnicas, conceituais e formais.

No dia 15 de dezembro, os estudantes realizaram uma mostra na UFSC de todos os vídeos produzidos no curso e, logo após, estes foram implementados na galeria de exposições, no portal do AVA-AD. Para finalizar, os participantes do curso avaliaram a proposta do núcleo de percepção visual, conforme pode ser observado nas transcrições abaixo.

De: carolina

Data: 2004-12-08 20:25:01

Título: Análise do curso

O ambiente virtual de aprendizagem a princípio me intimidou. Pensava que não me adaptaria e que o ensino seria maçante. Logo no primeiro contato meu preconceito foi quebrado. Sinto que me adaptei muito bem, adorei ler os textos disponibilizados sobre vídeo. Ainda sinto que me distraio facilmente lendo grandes quantidades de texto na tela, mas o uso de hyperlinks faz com que eu interaja com a interface, fazendo com que a leitura não se torne monótona. 
Achei ótimo discutir com meus colegas e com a professora Ana Maio através dos fóruns. Como eu escrevia constantemente sobre o que estava fazendo, refletia mais sobre minhas decisões. E ao expor as mesmas, discussões eram geradas elevando o processo criativo de todos.

Os textos colocados no material disponibilizado eram excelentes, pertinentes aos problemas. Era muito bom ter a segurança de poder acessar o cronograma, o método, os critérios de avaliação dos problemas a qualquer momento. Sobre poder interferir nos fóruns de outros grupos, achei excelente. Recebi um comentário de um integrante de outro grupo em um tópico por mim criado e achei ótimo.

De: Frank

Data: 2004-12-08 20:28: 20

Título: Avaliação do curso

O ambiente virtual contribuiu em muito no aprendizado sobre vinheta, fazendo o "papel" de complemento, auxiliando para, principalmente, tirar dúvidas. Questões pertinentes à percepção visual, entre outras, logicamente surgiram no decorrer da disciplina, e assim nós tivemos um meio a mais do que a sala de aula para saná-las, e aumentar ainda mais o conhecimento da matéria. $\mathrm{O}$ ambiente foi então, de grande valia para a realização não só do trabalho final, como também de conhecimentos gerais sobre Vídeo.

De: giorgia

Data: 2004-12-08 20:00: 18

Título: Giorgia comentando

Para mim, que não trabalho com vídeo, e não tinha muita noção de como as coisas funcionavam, a disciplina de vinheta + percepção visual foi muito interessante e esclarecedora. O AVA-AD é muito fácil de trabalhar e manusear. O conteúdo mostrado é objetivo e sintético, de fácil entendimento, como acho que devem ser as leituras feitas na tela do computador, já os materiais maiores eram disponibilizados para download e impressão.

Os fóruns de discussões eram muito válidos. O nosso trabalho final foi muito divertido e experimental, pois fomos aprender fazendo, começando a ter noção de tempo e os cuidados com iluminação, tamanho, cores, perspectiva, etc. Tive um grande aprendizado.

Quanto à percepção visual acho que fiquei muito mais crítica em relação ao vídeo, sabendo dos conceitos e definições, começamos a prestar atenção em detalhes que nunca havia reparado antes. Acho que o material audiovisual, o vídeo, é uma das ferramentas mais potentes e complexas de comunicação, sabendo de seus conceitos o manuseio desta ferramenta fica muito mais fácil e instigante.

De: fadinhaverde

Data: 2004-12-08 20: 16: 56

Título: Renée avaliação do curso 
A intervenção e auxilio da professora Ana foi bem proveitosa e enriquecedora pra aula. As visões mais técnicas e direcionamento produtivo do professor Augusto, foi complementada com o aprofundamento conceitual e questionador da Ana apoiadas pelo ambiente AVA-AD.

A minha relação com o ambiente foi mais intensa do que previ. Li todos os textos no inicio da interação, mas depois não mais os consultei talvez porque já havia absorvido todo o conteúdo, ou porque não senti necessidade de revisar. $\mathrm{O}$ elemento mais interessante oferecido pelo AVA-AD foi com certeza o espaço aberto para discussões. Os comentários e discussões geradas foram muito interessantes, por proporcionarem intervenção de todos os integrantes do grupo, mais a professora Ana (e quem quisesse claro) arquivando a evolução do nosso raciocínio, e contribuindo para a nossa evolução do vídeo.

\section{Considerações Finais}

Diante do exposto, pode-se sustentar que a estrutura do núcleo de percepção visual responde à questão norteadora deste estudo, ou seja, o que foi considerado, em termos teóricos, pedagógicos e tecnológicos, para que a aprendizagem concernente à percepção visual se efetive no contexto do AVA-AD.

No que se refere aos aspectos tecnológicos, defendeu-se a apropriação do potencial das tecnologias de informação e comunicação para a aprendizagem colaborativa a distância. Para tanto, os problemas implementados envolveram tarefas cooperativas, baseadas na participação ativa dos alunos para o alcance dos objetivos; assim, cada grupo de cinco estudantes analisou e criou vídeos por meio de etapas distintas, nas quais os participantes tinham que estar constantemente em contato entre si, com a professora e entre os grupos.

Identificou-se, então, que as atuais tecnologias de informação e comunicação possibilitam ao AVA-AD responder à atual demanda social por formação continuada e qualificação profissional. Por conseqüência, pode-se sustentar que a estrutura tecnológica desse modelo, por meio dos eixos de comunicação (e-mail, chat, fórum de discussões), documentação (banco de textos e imagens: vídeos, fotografias, animações; galeria de trabalhos dos alunos, material didático), informação (conteúdos, estudos complementares, dicas, bibliografias, sugestão de sites, artigos) e produção (problemas), dinamizou a promoção da autonomia, da interação e da gestão do conhecimento, no ambiente de aprendizagem.

Destaca-se que a estética do ambiente priorizou a criação de um lugar agradável e simples, com uma identidade visual harmônica que compreendeu interfaces amigáveis, cores atraentes, imagens variadas, ilustrativas das discussões teóricas e uma logística facilmente reconhecida.

Por efeito, o professor conta com muitos recursos para motivar os aprendizes à participação. Nesse caso, entendemos que a flexibilidade espaço-temporal associada ao bom uso desta pelo professor é o principal fator do processo motivacional. Considerando-se os critérios de avaliação adotados no curso, participação fundamentada nos fóruns de discussões e produto final, em relação aos resultados obtidos nas análises e nos produtos videográficos, pode-se concluir que houve aprendizagem, pois, além de resolver os problemas, os aprendizes:

a. demonstraram capacidade para adequar, articular e integrar aspectos teórico-práticos relativos à percepção visual, por meio da aprendizagem baseada nos problemas; 
b. aprofundaram o estudo da percepção visual na aplicação de análise de vídeos;

c. expressaram sensibilidade estética e artística na criação de vídeos de diferentes gêneros, focalizando o tema percepção visual;

d. demonstraram entendimento dos problemas propostos através da qualidade da participação nos fóruns de turma e de grupo, confirmando assim uma aprendizagem colaborativa a distância, por meio dos dispositivos tecnológicos disponíveis no núcleo de percepção visual, no AVA-AD.

No entanto, os benefícios do ciberespaço não se restringem à gama de dispositivos tecnológicos, mas antes dependem do uso que os atores humanos fazem disso, ou seja, dependem de atitudes, modos de pensamento, e, sobretudo, de valores sociais, éticos e estéticos.

\section{Referências}

ARNHEIM, R. Arte e percepção visual. São Paulo: Pioneira: Edusp, 1997.

BELLONI, M. L. Educação à distância. Campinas: Autores Associados, 1999.

BENAKOUCHE, T. Algumas idéias equivocadas e duas ou três questões sobre a Educação a Distância. Campinas, 2003. Texto apresentado no XI Congresso Brasileiro Sociologia, na Universidade de Campinas.

Tecnologia é sociedade: contra a noção de impacto tecnológico. Cadernos de Pesquisa, Florianópolis: Programa de Pós-Graduação em Sociologia Política da UFSC, n. 17, set. 1999.

CASTELLS, M. A sociedade em rede. São Paulo: Paz e Terra, 2000.

GUATTARI, F. Da produção de subjetividade. In: PARENTE, André. Imagem máquina. São Paulo: Ed. 34, 1996.

KASTRUP, V. Novas tecnologias cognitivas: o obstáculo e a invenção. In: PELLANDA, N. M. C.; PELlANDA, E. C. Ciberespaço: um hipertexto com Pierre Lévy. Porto Alegre: Artes e Ofícios, 2000.

LÉVY, P. A inteligência coletiva: por uma antropologia do ciberespaço. São Paulo: Loyola, 1998.

As tecnologias da inteligência: o futuro do pensamento na era da informática. Rio de Janeiro: Ed. 34, 1993.

O que é o virtual. São Paulo: Editora 34, 1996.

SANTAELLA, L. Cultura e artes do pós-humano: da cultura das mídias à cibercultura. São Paulo: Paulus, 2003 